\title{
Introducing BIM in Curricular Programs of Civil Engineering
}

\author{
Alcínia Zita Sampaio ${ }^{1}$ \\ ${ }^{1}$ University of Lisbon, Department of Civil Engineering, Lisbon, Portugal \\ Correspondence: Alcínia Zita Sampaio, University of Lisbon, Department of Civil Engineering, Lisbon, Portugal.
}

Received: March 19, 2021

Accepted: July 8, 2021

Online Published: July 9, 2021

doi:10.5430/ijhe.v11n1p31

URL: https://doi.org/10.5430/ijhe.v11n1p31

\begin{abstract}
Building Information Modelling (BIM) enables the Civil engineers professional to accomplish the digital requirements and also the integration and collaboration on the elaboration of projects and maintenance of buildings. BIM methodology is currently the main subject of investigation and application in the construction industry and the education have been exploring the introduction of this issue in curricular programs. The students of civil engineering and architecture, as future professionals, must updated their skills with the most recent innovative technology and knowledge. Several academies better classified within the architecture and engineer sector, were selected and its curricular programs were analyzed: the didactic strategies of inserting BIM teachings are similar in the main concept and practice, but depending of the expertize of the school, the aspects related to architecture, structures, construction or planning are deeper taught; the level cycles of introduction BIM (bachelor, master or postgraduate), the professional courses offered to architects and engineeres and the main subjects were discussed. The principal aim of the curricular research is the characterization of BIM education in distinct academies. A resume of actions and organization of topics that promotes an adequate updating of the students skills was achieved, helping BIM educators in their activity.
\end{abstract}

Keywords: BIM, curricula, higher education institutions, curricular cycles, BIM subjects

\section{Introduction}

Building Information Modelling (BIM) concept and practice are currently the most relevant procedure in a large range of sectors in the construction industry. The BIM tools available allow developing projects of buildings and infrastructures, planning the construction work or supporting the management activity of buildings, in a centralized, digital and collaborative way. The fundament of BIM is the generation of a geometric three-dimensional (3D) model composed of parametric objects (Succar, 2009). The capacity of BIM tools in creating parametric models with information concerning not just geometry and spatial relationships, but also properties of the applied materials, the geographic data, the costs estimation and the documents of warranties and certificates, keeps BIM use at the lead of exploring innovative working procedures (Youssef et al., 2013). In the construction industry, BIM have contributing to the decreasing of discrepancies between the planned work and the as-built construction, reducing costs divergences and avoiding errors (Milyutina, 2018).

The implementation of BIM is currently very well disseminated around the world in distinct sector of the Architecture, Engineering and Construction (AEC) industry. Finland was the first country mentioned an incipient notion of hierarchy systems of construction components. After that, in the years 70-80, the first idea was representing the construction components as objects, namely, a window belongs to a particular wall or a slab in located in a specific level in a building. The term "Building Description System", followed by "Building Product Models" and after by the designation "Product Information Models" were the background of the current "Building Information Modelling" term (Eastman et al., 2011). Nevertheless, the BIM expansion and embracing started in Finland, the tool development was crucial for the implementation, and, in this, USA introduced remarkable technological advances developing BIM based tools, with the capacity to materialize the genesis of the BIM concept. In this, the word BIM was adopted by commercial software houses for the construction industry and the advances in technology applied in BIM tools allows to develop better and efficient products (Vilutiene et al., 2019).

Around the world BIM methodology have been adopted mainly in public buildings (Sampaio, 2018): In Europe the first countries in using the methodology were Finland, Norway, Sweden and Denmark and they established some strategies and rules to support BIM collaborative environments (Muller et al., 2017), [8] (Ignatov et al., 2019). Other countries like Singapore and China were BIM is widely applied established new ifc objects related to buildings and 
railway and road projects (Liu et al., 2017), (Wang et al., 2018). The government action is initialized in the United Kingdom with the intention of reduce carbon emission in construction (Mohamed et al., 2020). Subsequently, currently the majority of the countries are studying governmental strategies in order to push the adoption of BIM, first in public buildings and after in all the projects of buildings and infrastructures (Sampaio et al., 2016).

Supporting the workflow needed in an integrated design process, the open BIM standard Industry Foundation Class (IFC) has an extraordinarily important role allowing the required interoperability, associated with the BIM competence (ISO 16739-1, 2018). The IFC type standardization was established by the international organization Building Smart and more complete and wide versions of IFC have been developed and applied in more efficient BIM software (Kiviniemi, 2015). The construction domain have been experimented a speedily changing technology, supported in continuous advances, refinements or improvements, in a wide perspective of methodology of work, platform of collaboration or way of delivery projects, mostly concerning BIM.

The students of Civil Engineering have taken benefit of the new opportunities in their future activity, adding BIM knowledge and with it improving their skills (BIM Strategy Report, 2012). Engineering teaching can be added with new BIM curricular learnings. In addition, specialists of civil engineering should also obtain capabilities in this new subject permitting the professionals to transfer experiences and lead it out of school, contributing to increase effectiveness in the development of projects and achieving optimized final products. Currently, training BIM in schools is necessary as the industry demands and requires it as imperative (Sadauskiene \& Pupeikis, 2018). The present study present a curricular analyses among the most relevant Civil Engineering schools in Europe including Portuguese academies and journals articles concerning BIM teaching in some of. A selection in Engineering Civil and Structural domains among European university was made and a detail of the top ranking classification is listed in Table 1.

Table 1. University rankings for Civil Enginnering 2020 (Ranking, 2020)

\begin{tabular}{clcc}
\hline Rank & \multicolumn{1}{c}{ University } & Country & Overall Score \\
\hline 8 & Swiss Federal Institute of Technology of Lausanne & Switzerland & 92.1 \\
23 & Polytechnic University of Catalonia & Spain & 84.6 \\
25 & Polytechnic University of Turin & Italy & 84.2 \\
38 & Polytechnic University of Madrid & Spain & 81.6 \\
$51-100$ & University of Lisbon & Portugal & - \\
$51-100$ & University of Porto & Portugal & - \\
\hline
\end{tabular}

The methodology to support the present study is based on a curricular program research, available on each of the listed Universities, with the objective of finding in each new or adopted unit how BIM subject is included, and in what curricular level. Other didactic actions were analyses in their context, as professional courses and workshops, and also in master thesis. The curricular analyses allows to resume new units and units that were adapt, the curricular levels were each proposal is insert and the most relevant courses (master, professional or workshops) offered by the universities.

This particular selection of universities and the final resume of units (optional and mandatory) and courses (master and professionals, partial or complete) can support new BIM educators to defined adequate strategies to applied in their universities the teaching of BIM subject. A first bibliographic research was made concerning the approaches implementation applied in several universalities organized by curricula adaptation, training on handling BIM tools and accomplish industry requirements. This structure helps readers to follow the distinct perspective applied in the listed academies, and reported in each paper. The propose of the present study is deeper in analyses concerning the subjects of the units and the courses. This detail bring a structured curricular program that can be easy adopted in other schools, depending of the expertize of the academy or the interested of the teacher.

\section{Academic Strategies to Introduce BIM}

This study demonstrates that the approaches established by the selected universities are distinct, elaborated considering the diversity of main objectives and studies (structures, construction, bridges or roads) of each one. However, the main concepts as parametric modeling processes and collaborative way of working are common to all proposals of every school (Sampaio, 2018a). However, inserting BIM into civil engineering curricular programs have not reached all teachers as the adoption of this new concept and way of designing requires time, dissemination and recognition of its benefits. As so understanding the principal barriers inside, each academy is pertinent to BIM 
education (Kevin \& Burr, 2009). The capability of higher education to adopt new training procedures attending to industry demand, imposes a rapid development within formal academia as well as education solutions offered outside the scholl (Sacks \& Pikas, 2013). In a background bibliographic review, concerning BIM education, three main perspectives were carried out:

- Curricular plan adaptation: New and experimental teaching approaches in BIM education have been added and developed combining the BIM issue in traditional courses. BIM education models vary widely among Universities, but mainly they are particular concentrated on the adoption of BIM subjects in the first curricular cycle in civil engineering degree. By establishing new standard plans specifically oriented for BIM courses, students learned the main principals and practice around the multidisciplinary workflow involved in a project. Woo (2006) describes some principal aspects introduced in construction educational environments and the innovative pedagogical challenges that BIM imposes. Molavi \& Shapoorian (2012) refer that teachers are committed in inserting new technologies related with BIM and mentioned distinct guidelines for BIM education. For that, concerning curriculum subjects and advanced software are used in teaching, and some experienced difficulties related to policy and practical procedures. In a collaborative and integrated project, the use of a centralized BIM model throughout the development of multi disciplines (architecture, engineering, construction, and facilities management) is need. This requirement has conducted to enhance distinct courses of action in undergraduate levels or even through graduate education (Lu et al., 2013). Gerber et al. (2015) present the conclusions of an analyses of a survey made among the students in order to understand and evaluate the use of the most advanced technologies in civil engineering curricula. The study indicates that all programs consider BIM is a very important topic for the future of the engineering education. Suwal et al. (2014) refer that most of the academy of Civill engineering in Finland, have been introduction BIM education for a long time, conducting to a generalized knowledge of using BIM tools in real projects, affording benefits to the construction industry. A research work conduct by Sadauskiene \& Pupeikis (2018), concerning the curricula analyze related with BIM, in higher education institutions, in Lithuania, shows that the strength of BIM development is the interdisciplinary established in school in order to joint disciplines in a semester project.

- Practical training: Supplemental teaching materials in BIM context helps to reinforce foundational concepts such as plan reading, estimating, scheduling, and construction coordination, based in BIM tools training. The benefits of BIM implementation are currently well disseminated in all sectors of the construction activity and as so the related concept and practice must be taught at the academies of civil engineering and architecture (Joannides et al., 2012). As the BIM methodology has been applied with increasing importance in the industry, it is of greatest relevance for teachers to incorporate it in their classes. The pedagogic approaches introduced by some academies allows students to increase their skills and capabilities, new knowledge that in the future they are going to use and domain with propriety on the execution of their activities. Namely, students are introduction on software experience with building planning and clash detection between disciplines in a project $\mathrm{Wu}$ et al., 2018). BIM tools support to integrate design process, where information is transferred between computer application, throughout the development of all tasks involved in the project lifecycle, and as so training students in several BIM tools is mandatory. Acquiring knowledge concerning the capacities and applicability of the available software with advanced technologies permits students or professional to provide learning BIM, concept and training, of any level of knowledge (Dossick et al., 2014

- Industry demand: Short courses were organized in order to undertake the need of the wide range of professionals of the industry. This type of actions have become urgent to be satisfied by the academies of civil engineering. Faust [29] (2018) recognizes the relevance of BIM education to accomplish the construction sector suggestions and needs and as a first step, a unit concerning an introduction to the application of BIM, management of construction projects, was implemented in the John Brown University, Arkansas, USA. The author intents to start a link with other teachers and academies in order to observe and change didactic experiences that could me useful the BIM teachers community. The proposal presented by (Sampaio, 2017) in a technical faculty goes through several aspects of BIM concept and application contributing to an suitable dissemination among civil engineer students and engineers in their real activity, as the topics taught goes from modeling buildings to their maintenance. Saleeb et al. (2016) refers to the increasing partnership among the industry and the colleges of engineering as a support to delaine us full new units, new modules, even complete masters or punctually specific workshops adequately oriented to the real needs verified in the sector. In particular, Peterson et al. (2011) mention that the upgrading inside 
school in curricular programs on a computing context, must constantly incorporate the most current technological advances that can be applied in the construction domain. For that it is recommended to invite BIM specialist who already has experience of applying the methodology in their real activity and in the diverse valences covered in construction (buildings, roads or dams).

Following this background, the introduction of BIM teaching in new or adapted didactic proposals in the traditional way of teaching presents currently some barrier. What was found in the curricular programs taken from each university listed in the next item is that some adaptations were performed at the higher levers of the courses and, with an even more expression, as complete courses offered to professionals outside the school. The academy and the teachers must follow the necessity of adding BIM subjects oriented to improve the skills of the students and to updated the knowledge of professionals that require to learn BIM subjects.

\section{Curricular Programs on Civil Engineering}

Training in BIM methodology is being introduced at high speed in all countries, making the required maturity achieve a higher level. The knowledge of BIM among construction professionals is no longer just resumed to a three-dimensional (3D) geometric model, but they have conscience that managing BIM information adequately, improves the quality of their conclude products. Engineers and architects, and all specialists involved in the development of projects and in the effective execution of the building, must become aware of the real advantages of the application of BIM in their specific activity, so that they can add value to the final result of each partner, contributing to the optimization of the final product.

Some of consulted formal didactic plans among several academies, teaching the new issue was found, but in all different attitude concerning BIM adoption was verified. Some introduces BIM subjects as just a mention in the lower level, others in the master level, and even just in specialized professional oriented to structures, construction or sustainability. The goal is always to add value to the technological capacity and knowledge of students, at each level of learning, or technicians who work in their activity, outside the school.

Several academies were selected, among a top ranking of universities in the domain of Civil Engineer, from Switzerland, Italy, Spain and Portugal, with the objective of analyzing the adaptation to BIM in their curricula. The report explores curricular programs to help to identify pedagogical strategies and challenges associated with the introducing of BIM training in schools, contributing to create relevant skills and competencies in future architects and engineers. In the present analyses, it was found that the master cycle, of several universities with civil engineering study, includes, in their curricular programs, optional BIM units or only BIM modules within informatics or technical drawing disciplines. It was also found that often students complement their education, developing final projects in BIM units and MSc research, empowering their skills with BIM knowledge. In addition, complementary outside courses in BIM have been offered, in order to support the needs that professionals in the sector asked for. The study reviews the current approaches to incorporate BIM into degree and certificate programs in leading international universities.

\subsection{Swiss Federal Institute of Technology of Lausanne}

At the Swiss Federal Institute of Technology of Lausanne, civil engineering students learn the main concepts of project, planning, construction and maintenance of buildings, railways and roads (Gerber et al., 2015). In addition to these main topics the recent study plans, refers that concerning the bachelor cycle it does not include yet the BIM issue, but optional units with BIM topic are offered in the master curricular lever and a complete A specific professional course was also found:

- In bachelor cycle - The computer-aided engineering unit introduces the basic computing requirements and practice, namely, programming languages, knowledge supporting decisions and machine learning, but no BIM is taught.

- In master cycle - Numerical representation and BIM, an optional unit, includes issues regarding the generation of BIM structural models using parametric objects included in libraries and promotes several aspects related with BIM, namely, digital database, collaborative work and management of structural projects.

- In master cycle - The summary of an optional unit regarding the BIM subject starts with the basic notion BIM (parametric modeling), followed by the applicability of the methodology with a more deep study evolving practice of the architectural project at a global scale. Several topics are taught: IFC standard and interoperability capacity; level of detail or development (LOD); BIM in project teams of architects and civil engineers; BIM based software training (ArchiCAD, Revit, Revizto and Open BIMconcept); construction 
schedules (4D) and building estimation costs (5D). The BIM unit is oriented to the presentation of BIM as a collaborative and integrated platform.

- In master thesis - Students apply the previous BIM knowledge on real building or infrastructures cases on the development of research work within master cycle.

The Swiss Federal Institute of Technology of Lausanne doesn't included BIM topics in the yearly cycles but only near the end of the academic training.

\subsection{Polytechnic University of Catalonia}

At the Civil Engineering academy of the Polytechnic University of Catalonia in Barcelona, the degree in Civil Engineer carries relevant educational formative contents of a range of sectors in engineering like infrastructures, construction, structural analyses, hydraulic topics, and a robust support in elementary sciences. The master level offers a wide range of subjects related to the diverse activity of a civil engineer, but the units found in the current curricular plans of both cycles, bachelor and master, does not include any reference to BIM. Only in professional masters complete specialized BIM courses are offered (Picó, 2009).

- In bachelor cycle - No BIM is taught in units like metric geometry and representation systems, wuth subjects similar to BIM computer issue. The summary only contemplate the capacity of understanding spatial vision and the skills to define technical drawings using CAD system.

- In master cycle - The technical drawing design and numerical calculation unit, offered as optional, aims the intention of introduction the basic knowledge concerning the use and programming of computers. It also includes data structure of graphical files, techniques of exporting file and introduction to 3D geometry and handle a CAD tool in the generation of drawings and 3D models, but without making any reference to BIM.

- In professional master - A new professional about BIM modelling of building construction is offered. The contents of the course refers to the understanding of the organization, management and coordination of teams and integrated works when supported on BIM collaborative platforms. A practical training component related with the generation of BIM models, of distinct disciplines is also considered.

- In professional master - Another specific professional program, involving the control of facility management services activities developed in BIM environments is outlined. Distinct topics mainly oriented to collection, researching, and transferring of data, and the handling of BIM software were found.

- In professional master - The professional course in structures aims to provide engineers with methodological knowledge, appropriate data transfer processes and obtaining the written and graphic documentation required in the structural project, using BIM-base software.

The Polytechnic University of Catalonia in Barcelona doesn't included BIM topics in the yearly cycles but it presents several professional master oriented to distinct speclities.

\subsection{Polytechnic University of Turin}

The Faculty of Civil Engineering of Polytechnic University of Turin presents a curricular program aiming the objective of teaching design, construction, management and maintenance of buildings and infrastructure (Donato, 2017). This Faculty is the first academy in introduction the BIM subject at the bachelor level. This is motivated by the government's introduction of a demand, at the level of the public buildings project, for the adoption of BIM. Thus, the school had to adapt and include, therefore, in the first year of schooling its concept. In addition, several professional courses were created.

- In bachelor cycle - The technical sketching unit presents only the drawing as a basic language of communication and the use of CAD tool the generation of drawings and geometric models. In addition, notes on methods of BIM with reference to the construction industry were included.

- In master cycle - The new unit of BIM subject, created within a specific master oriented to the built structures, summarize the objective of bringing students to obtain the sufficient skill in BIM allowing them to develop projects of building and support the maintenance activity.

It was found at the Polytechnic University of Turin a first mention to BIM topic. The academy presents a complete master in BIM but oriented to build structures.

\subsection{Polytechnic University of Madrid}

The faculty of Civil Engineering of the Polytechnic University of Madrid presents a wide range of topics of interest 
for the activity of engineers with a relevant theory and practical components. No BIM is taught at the bachelor level, but a new master BIM unit oriented to the management aspect of a building was created (Lozano-Díez et al., 2018):

- In bachelor cycle - The summary of the graphic expression unit develops spatial vision capacity and graphical expression techniques based on descriptive geometry and computer-aided design programs, but BIM is not taught.

- In master cycle - The unit concerning built constructions in a management context, summarizes the capacity of exchanging and interconnecting the management of the project lifecycle of international work using BIM tools. The content involves: concept, applications, BIM software available, generation and handling BIM models and the workflow of data required in a collaborative BIM project.

In the Polytechnic University of Madrid no BIM topic is teached. The academy presents a master course were the basic concept and the training of BIM software were teached.

\subsection{University of Lisbon}

At the Department of Civil Engineering of the University of Lisbon, the formal curricular program allows students to be prepared to their future professional activity, accomplish the demand of the construction sector. At the first year of the degree, the students learn the basic concept of BIM methodology and how to handling a BIM modeling software (Sampaio, 2015) and currently short courses concerning BIM concept and applicability are offered to professionals of the sector Sampaio \& Martins, 2021). Several MSc theses have been also developed, in the past 10 years, comprising a wide range of topics (Sampaio, 2018b) and a new BIM unit begun on 2021 to be offered (Sampaio, 2019).

- In bachelor cycle - The computer-aided drawing (CAD) unit concerns the use of CAD tools on the creation of technical drawing applied in civil engineering and a basic introduction to BIM methodology is presented with a practical component on the generation of the architectural and structural components of a BIM model (Figure 1).
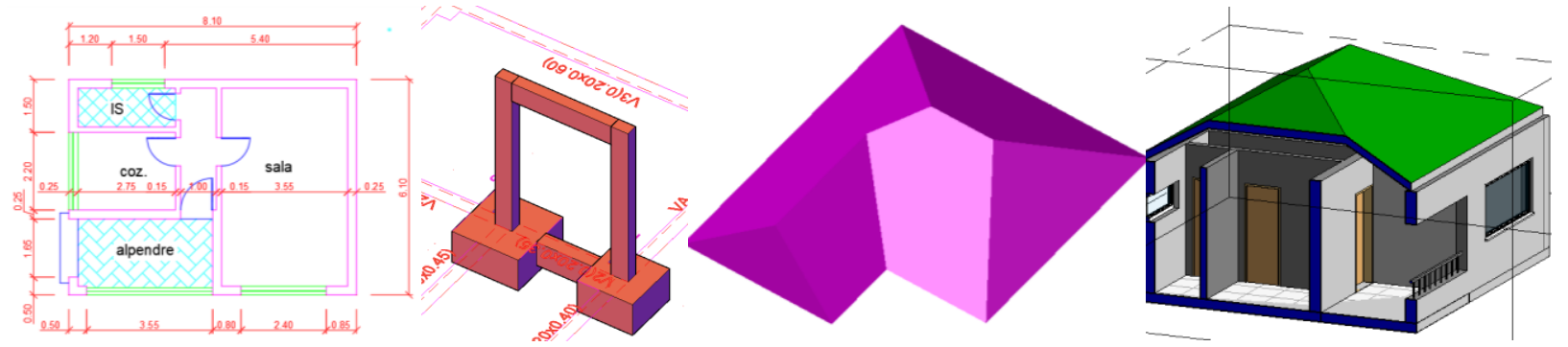

Figure 1. Drawings and models created by students in CAD unit

- In master cycle - The proposed unit concerning BIM methodology presents a summary oriented to parametric modeling concept, handling a BIM tool as a practical aspect and the introduction to collaborative projects. The curricular content involves a modelling practice concerning the areas of structure, plumping, budgeting and drawing.

- In short courses - The school offers short courses concerning BIM demand by the professionals of the construction industry, covering distinct sectors of civil engineering mainly construction planning, structural analyses, geotechnics works management and maintenance of buildings (Figure 2).

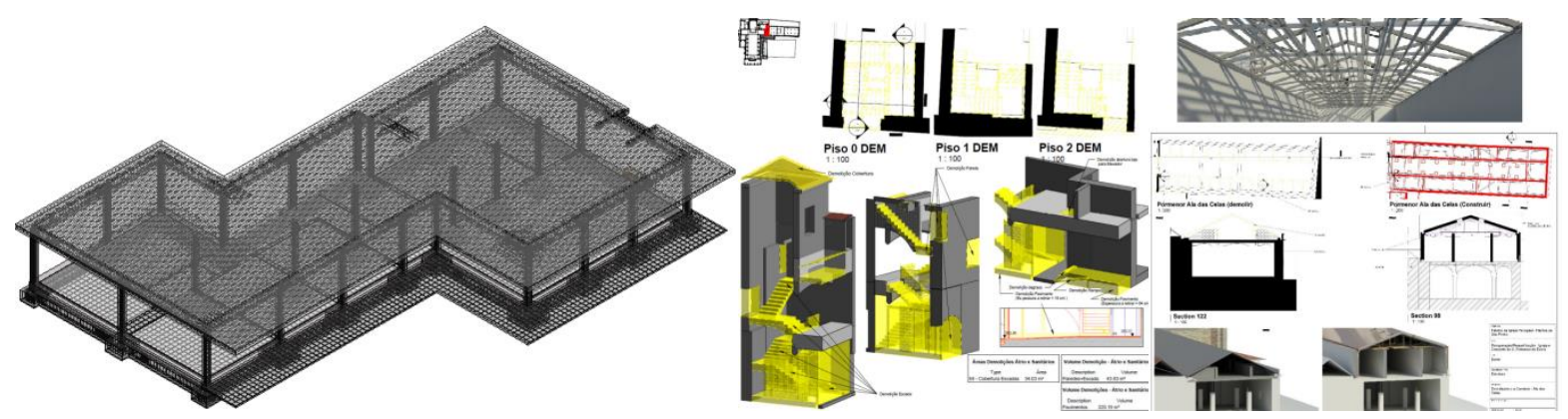

Figure 2. Images of short courses presentations 
- In students'workshop - The BIM workshop offered by the school was demanded by finalist students. The BIM one-day course promotes the increase of knowledge in BIM, useful in the training of students and, later, in their activity as engineers, becoming better prepared and qualified to achieve greater success in the work. The content of the course concerns a practical component and a large sample of the applicability of (Figure 3).
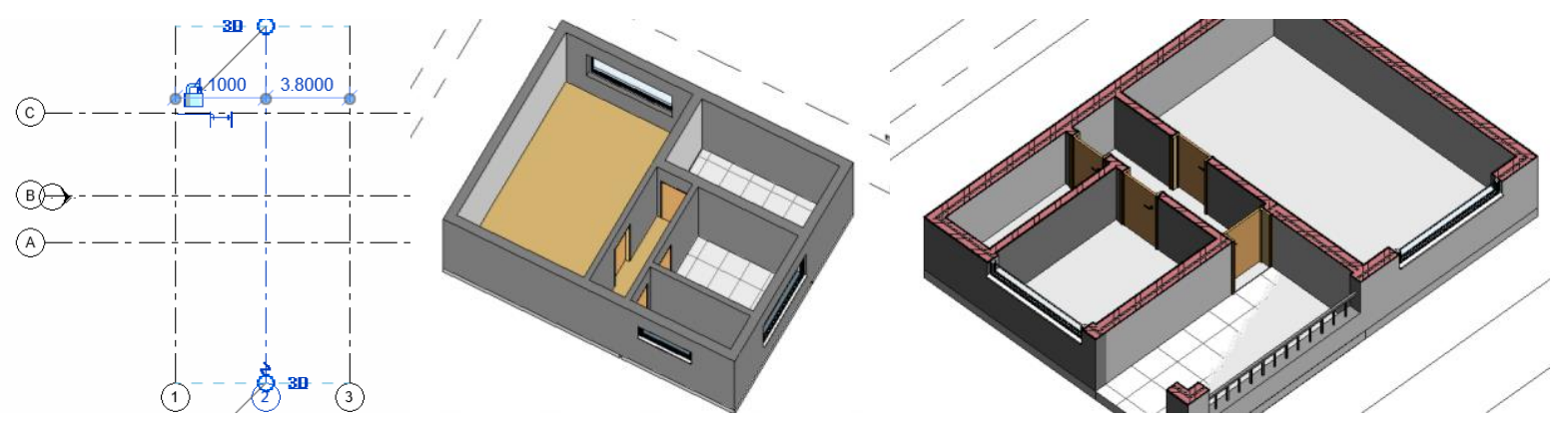

Figure 3. Images presented in workshop concerning the use of a BIM software

- In master theses - The introduction of BIM methodology is based on the generation and handling BIM models developed in a didactic context. The range of application of the studies reaches several transversal disciplines: BIM in transport infrastructure; BIM in structural design; BIM in geotechnics project; interoperability analyses in structural design; comparative analysis of measurements of quantities in traditional and BIM project; generation and certification of BIM parametric objects of floors, walls and roofs (Figure 4).

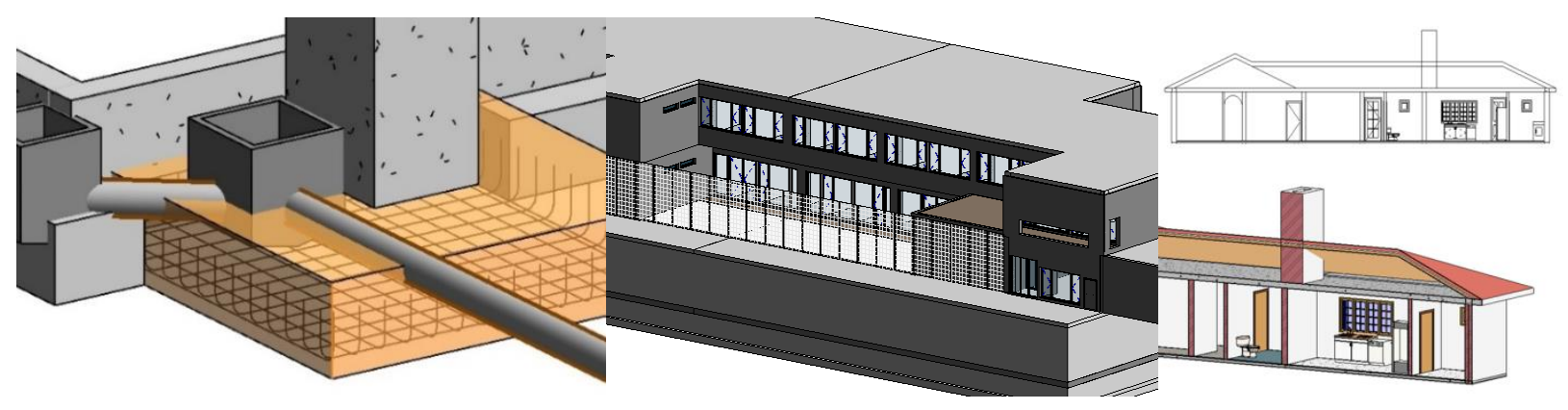

Figure 4. Imagens from MSc theses

In the University of Madrid a few years ago the BIM topic have been introduced in Technical Drawing unit, offered to students of the first year. A complete unit is proposed and the first year to be applied in 2021/22. However, along the last 10 years master thesis and workshops concerning BIM have been developed with a great participation of students and professionals. The images of the figures illustrate the results of the classes and of the masters thesis, and also some of the presentation slides of the shorts courses.

\subsection{University of Porto}

Concerning the degree of Civil Engineering the University of Porto presents a large range of topics highlighting a relevant relation between academy and industry. It was found that the bachelor cycle does not comprise BIM subject but in the last semester of the course two BIM issues were incorporated:

- In bachelor cycle - At the first level of education no BIM is taught. The technical drawing unit aims to present the drawing as a technical language based in rules, required to communicate to partners in the development of a project and to transmit digital documents of the project. Just CAD software is used in classes.

- In master cycle - The optional computing in construction unit refers to BIM in building as an advanced technology. The unit concerns mostly the understanding BIM application in project, construction planning, budgeting, maintenance and rehabilitation. It also includes to handling of a BIM modeling tool and multifunctional platforms as the main support to manage models, coordinate projects and to communicate with all the stakeholders. 
- In master cycle - The master course about information systems in building introduces the digital data management concept in construction, identifies the required workflows in the development of several construction process, and analyses the construction companies, offices and enterprise requirements in the development of construction products.

Finally, in the University of Porto, no BIM is taught in the first years, but a unit and master course are currently offered to students

\section{Curricular Discussion}

BIM methodology education followed the construction industry needs. Teaching BIM comprises a large range of topics mainly concepts, tools and workflow of data. Consulting several curricular programs of specific units and courses related to this issue allows pointing some strategic lines of organizations, objectives and contents. In its BIM educational proposals accomplish the construction industry demands. The general objective of introduction BIM subjects in school is to allow students and professionals, an appropriate understanding of the methodology and its applicability. Therefore, teachers involved in units similar to drawing or informatics are the first actors, and as so they are more pressed to participate in adopting BIM training, concept and practice in their educational activity. The organization of the present text underlies the main remarks and identifies BIM contents illustrating the didactic strategy followed by each school:

- In bachelor cycle - CAD systems are used in all academia but just at the ULisbon and at the PUTurin, a rudimental introduction to BIM is made in Civil Engineering courses. In fact, at this level just an incipient concept of 3D modelling, based in parametric objects, can be taught. However several units of all schools provide the use of CAD system in drawings (2D) and 3D models.

- In master cycle-BIM has not been introduced in ULisbon and in UPCatalonia and just a proposal of a BIM unit was elaborated to be inserted in ULisbon.

- In master cycle - BIM was introduced as a new unit in the Universities of Laussanne, Madrid, Turin and Porto as mandatory or optional.

- In professional or specialization masters - In the Polytechnic University of Catalonia, BIM subject was inserted in the Control of facility management services master as a complete unit.

- In short courses or workshops - several one-day courses were organized at the University of Lisbon concerning BIM aimed at professionals in the sector and finalist students in engineering

- In master theses - In all academies several master thesis were developed along the last 10 - 15 years, focused in a wide range of topics.

From the curricular study, it is possible to point relevant issues concerning BIM contents and objectives:

- Basic concepts - common to all didactic strategies it was found the introductory subjects of BIM as well a practical component. The BIM methodology concept, applications and revision of BIM software is first mentioned, followed by the centralization of information, integration of processes and notion of collaborative project based on the organization of BIM teams of architects and civil engineers. Other basic topics are related with follow-up work and monitoring, implementation and workflow of data, IFC standard and interoperability capacity. Moreover, the range of applicability of the methodology, reveling limits and benefits, are described.

- $\quad$ Practice - the engagement of students and participants in professional courses is supported on handling diverse type of BIM based software, incrementing their skills in computing. The architectural, structural and MEP components of a BIM model were generated using modelling BIM software (Revit, ArchiCAD, Allplan or AECOsim) and the conflict analyses between disciplines is made using Navisworks. The verification of the interoperability capacity of the software was made over ArchiCAD/Revit, Revit/Robot and Revit/Revizto transfer based on bi-directional workflow data. The reference to BIM collaborative platform available is made in order to manage all disciplines of a complete project and to integration in an efficient way all multitasks required in a building lifecycle.

- $\quad$ Specific subjects:

- Structures: In a structural project, the principal aspect taught concerns the interoperability limitation. Structural project is developed using Robot, ETABS, SAP, Cype, and Tricalc, and the cases studies involves buildings, bridges, tunnels, metro stations, schools or hospitals. 
- Construction: In the construction process, the planning, the measurements and the budgeting are essential topics that are taught. It requires the generation of 4D models (construction schedules) and of 5D model (extraction of quantities of materials and estimation costs). In these tasks virtual and augmented reality technologies can be used.

- Maintenance and facilities management: The maintenance and management tasks required in a building can be supported in an integrated and collaborative BIM platform. A complete BIM model supports facilities management of the building including maintenance (7D) and several type of analysis aimed the optimization of buildings performance like sustainability or energetic simulations (6D).

Nevertheless, some conservative mentality of the higher education lecturer, a speed implementation of BIM subjects were found, mainly in the last curricular level in Civil Engineering degree, and in specific masters and professional courses organized in close collaboration with the industry. The upper list of contents, organized by cycle levels and subjects, clearly identify the strategies adopted by each university and support other proposals that teachers desired to implement in their academy.

A remark relevant that should be changed in all the universities concerns the necessity of introduction the handling of BIM-based tools in the yearly level of Civil Engineer courses. The young students learn easily how to manage new software and its features. However, the real benefits of BIM should be transmitted to students after in the last cycle level. To the professionals that demand specific direction of BIM application, the teachers of the academies must organize courses or workshops with subjects and expertizes oriented to the required demand from distinct sectors, namely, structures, construction, management of projects or maintenance of buildings activity.

Follow the main discussion the incipient introduction to BIM are well accepted by the young students, but the real potential of the BIM methodology is better understand by the students that are near to go to the profession out of the academy. For the final students, the specific subjects, like construction, management or infrastructures, are better known and BIM can be thought in deeper level and large range of application.

\section{Conclusions}

The text discusses the effort of the academy to be up to date with the most recent computing innovations applied in the construction sector. The academies, as a first mission, define didactic approaches of transmitting BIM knowledge to students, but also professionals of the industry demands this request. An over view of the adaptation of curricular programs was first identified among distinct academies follow three main orientations: adaptation of curricular programs; training on handling tools; fulfill industry needs.

With the main objective of identify how universities and polytechnics contribute to introduce BIM in their organizations, a deeper research by university, by unit and by contents was carried out in order to identify a major absent concerning the introduction of the practical part at the first cycle, and after the offer of courses of distinct expertise to professionals. In it, several courses were analyzed and the main issues were identified:

- An initial subject concerning concept and applicability is introduced;

- Followed by a practical experience on the generation of BIM models, using the available BIM-based tool and on the use of BIM data to achieve multi-tasks developed over the model;

- From the analyses of the syllabus and type of units and courses offered to students and professionals, several remarks can be worked out, associated to the preferences of the universities, manly, more comprehensive courses or following management, construction or infrastructures perspectives;

- And finally, it is also attended, the collaborative characteristic of BIM in the definition of large teams involving several disciplines, in the development of collaborative works supported in BIM platforms.

\section{References}

BIM Strategy Report (2012). BIM management for value, cost and carbon improvement. A report for the Government construction client Group, BIM working party strategy paper, https://www.cdbb.cam.ac.uk/system/files/documents/BISBIMstrategyReport.pdf

Donato, V. (2017). Towards design process validation integrating graph theory into BIM. Architectural Engineering and Design Management, 13(1), 22-38. Ed. Taylor \& Francis. https://doi.org/10.1080/17452007.2016.1208602

Dossick, C. S., Lee, N., \& Foleyk, S. (2014). Building information modeling in graduate construction engineering and management education, Computing in Civil and Building Engineering, 2176-2183. 
https://doi.org/10.1061/9780784413616.270

Eastman, C., Teicholz, P., Sacks, R., \& Liston, K. (2011). BIM Handbook: A Guide to Building Information Modeling For Owners, Managers, Architects, Engineers and Contractors, John Wiley \& Sons, Inc. ISBN: 978-0-470-18528-5, Chichester, United Kingdom.

Faust, R. (2018). BIM curriculum development, AiC $13^{\text {th }}$ BIM Academic Symposium, 2018, Las Vegas, USA, https://aicbimed.com/files/bimas2016proceedings.compressed-2.pdf\#page $=122$

Gerber, D. J., Khashe, S., \& Smith, I. F. C. (2015). Surveying the Evolution of Computing in Architecture, Engineering, and Construction Education, Journal of Computing in Civil Engineering, 29(5), (septembre 2015). https://doi.org/10.1061/(ASCE)CP.1943-5487.0000361

Ignatov, I., \& Nørkjær-Gade, P. (2019). Data Formatting and Visualization of BIM and Sensor Data in Building Management Systems. $19^{\text {th }}$ International Conference on Construction Applications of Virtual Reality, 13-15 November 2019, Bangkok, Thailand. https://www.researchgate.net/publication/337274994_Data_formating_and_visualization_of_BIM_and_sensor_ data_in_building_management_systems

ISO 16739-1 (2018). Preview Industry Foundation Classes (IFC) for data sharing in the construction and facility management industries -- Part 1: Data schema, International Organization for Standardization (ISO). https://www.iso.org/standard/70303.html

Joannides, M. M., Olbina, S., \& Issa, R. R. A. (2012). Implementation of Building Information Modeling into Accredited Programs in Architecture and Construction Education, International Journal of Construction Education and Research, 8(2), 83-100, 2012. https://doi.org/10.1080/15578771.2011.632809

Kevin L., \& Burr, E. D. (2009). Creative Course Design: A Study in Student- Centered Course Development for a Sustainable Building/BIM Class, Associated Schools of Construction, Annual International Conference. http://ascpro0.ascweb.org/archives/cd/2009/paper/CERT82002009.pdf

Kiviniemi, A. (2015). Experiences from the BIM-Adoption in Finland and UK-Clients as the drivers of innovation, University of Liverpool, School of Architecture, 1-45. https://docplayer.net/31610531-Experiences-from-the-bim-adoption-in-finland-and-uk-clients-as-the-drivers-ofinnovation-prof-arto-kiviniemi-school-of-architecture.html

Liu, B., Wang, M., Zhang, Y., Liu, R., \& Wang, A. (2017). Review and Prospect of BIM Policy in China, IOP Conf. Series: Materials Science and Engineering, 245(2017) 022021, IOP Publishing, ISSN: 1757-899X. https://doi.org/10.1088/1757-899X/245/2/022021

Lozano-Díez, R., López-Zaldívar, O. S., Herrero del Cura \& Mayor-Lobo, P. (2018). First formal training experiences in the BIM environment. The case of the Degree in Building in the Universidad Politécnica de Madrid, Advances in Engineering Education, 2(1), 109-121, ISSN: 2530-7940. https://doi.org/10.20868/abe.2018.1.3697

Lu, W., Peng, Y., Shen, Q., \& Li, H. (2013). Generic model for measuring benefits of BIM as a learning tool in construction tasks, Journal of Construction Engineering and Management, 139(2), 195-203. https://doi.org/10.1061/(ASCE)CO.1943-7862.0000585

Milyutina, M. A. (2018). Introduction of Building Information Modeling (BIM) Technologies in Construction, Published under licence by IOP Publishing Ltd, Journal of Physics: Conference Series, 1015(4), 1015042038. https://doi.org/10.1088/1742-6596/1015/4/042038

Mohamed, A. G., Abdallah, M. R., \& Mohamed, M. (2020). BIM and Semantic Web-based Maintenance Information for Existing Buildings. Automation in Construction, 116, 103209. https://doi.org/10.1016/j.autcon.2020.103209

Molavi, J., \& Shapoorian, B. (2012). Implementing an Interactive Program of BIM Applications for Graduating Students. ICSDEC 2012 - Developing the Frontier of Sustainable Design, Engineering, and Construction (Chong et.al, Ed.), Fort Worth, Texas, USA. 1009-1016. https://doi.org/10.1061/9780784412688.119

Muller, M. F., Garbers, A., Esmanioto, F., Huber, N., Rocha, E., \& Canciglieri, O. (2017). Data Interoperability Assessment Though IFC for BIM in Structural Design: A Five-year Gap Analysis, Journal of Civil Engineering and Management, 23(7), 943-954. https://doi.org/10.3846/13923730.2017.1341850

Peterson, F., Hatman, T., Fruchrer, R., \& Fischer, M. (2011). Teaching construction project management with BIM support: experience and lessons learned, Automation in Construction, 20, 115-125. 
https://doi.org/10.1016/j.autcon.2010.09.009

Picó, E. C. (2009). Introduction to BIM technology, book, ed. Polytechnic University of Catalonia, ISBN-10: 8495249448, ISBN-13: 978-8495249449. https://www.abebooks.com/9788495249449/Introducci\%C3\%B3nTecnolog\%C3\%ADa-BIM-Coloma-Pic\%C3\%B3-8495249448/plp

Ranking (2020). QS world University ranking QS World University Rankings for Engineering - Civil and Structural 2020 | Top Universities.

Sacks R., \& Pikas, E. (2013). Building Information Modeling Education for Construction Engineering and management. I: Industry Requirements, State of the Art, and Gap Analysis, Journal of Construction Engineering and Management, 2013. https://doi.org/10.1061/(ASCE)CO.1943-7862.0000759

Sadauskiene, J., \& Pupeikis, D. (2018). Review of BIM implementation in Higher Education, Journal of Sustainable Architecture and Civil Engineering, 1(22), 99-109. https://doi.org/10.5755/j01.sace.22.1.21116

Saleeb, N., Dafoulas, G., \& Loomes, M. J. (2016). The role of architectural design in virtual worlds for educational purposes. $9^{\text {th }}$ International Conference on ICT, Society and Human Beings (part of MCCSIS 2016: Multi Conference on Computer Science and Information Systems), Funchal, Portugal, https://core.ac.uk/download/pdf/83949046.pdf

Sampaio, A. Z., \& Gomes, A. M. (2021). BIM Interoperability Analyses in Structure Design, MDPI - Civil Engineering, 2(1), 174-192. https://doi.org/10.3390/civileng2010010

Sampaio, A. Z. (2015). The Introduction of the BIM Concept in Civil Engineering Curriculum, Special issue: Engineering Education: Beyond Technical Skills, Part II-Case studies linked to the promotion of specific technical skills, International Journal of Engineering Education, 31(1-B), 302-315, ISSN 0949-149X/91. https://dialnet.unirioja.es/servlet/articulo?codigo $=6922062$

Sampaio, A. Z. (2017). BIM as a Computer-Aided Design Methodology in Civil Engineering, Journal of Software Engineering and Applications, 10, 194-210. https://doi.org/10.4236/jsea.2017.102012

Sampaio, A. Z. (2018). Enhancing BIM Methodology with VR Technology, book: State of the Art Virtual Reality and Augmented Reality Knowhow, Intechopen, Edited by Nawaz Mohamudally. https://doi.org/10.5772/intechopen.74070

Sampaio, A. Z. (2018a). Introduction of BIM methodology in education: Concept and application, HEAd'18, $4^{\text {th }}$ International Conference on Higher Education Advances, Ed. Universitat Politècnica de València, Valencia, Spain, June 2018, 19-27. https://doi.org/10.4995/HEAD18.2018.7443

Sampaio, A. Z. (2018b). Building Information Modeling (BIM) applications in an education context, Book: Advanced Computing Strategies for Engineering, EG-ICE 2018, LNCS 10864, I. F. C. Smith and B. Domer (Eds.): EG-ICE 2018, LNCS 10864, pp. 414-428, 2018. https://doi.org/10.1007/978-3-319-91638-5_23

Sampaio, A. Z. (2019). Proposal of curricular program to introduce BIM in a Civil Engineering school, book: Springer International Publishing AG, part of Springer Nature 2019, HELIX 2018, Innovation, Engineering and Entrepreneurship, 1131-1137, 2019. https://doi.org/10.1007/978-3-319-91334-6_156.

Sampaio, A. Z., Simões D. G., \& Berdeja, E. P. (2016). BIM tools used in maintenance of buildings and on conflict detection, Book: Sustainable Construction: Building Performance Simulation and Asset and Maintenance Management (Vol. 8), (Ed.) J. Q. Delgado, Springer-Verlag, Springer book series: Building Pathology and Rehabilitation, March 2016, ch.8, 163-183. https://doi.org/10.1007/978-981-10-0651-7_8

Succar, B. (2009). Building information modeling framework: A research and delivery foundation for industry stakeholders, Automation in Construction, 18, 2009, 357-375. https://doi.org/10.1016/j.autcon.2008.10.003

Suwal, S., Jäväjä, P., \& Salin, J. (2014). BIM Education: Implementing and Reviewing OpenBIM - BIM for Teachers, Computing in Civil and Building Engineering, ASCE 2014, Paper w78-2014-paper-267, https://doi.org/10.1061/9780784413616.267

Vilutiene T., Kalibatiene D., Hosseini M. R., Pellicer E., \& Zavadskas E. K. (2019). Building Information Modeling (BIM) for Structural Engineering: A Bibliometric Analysis of the Literature, Advances in Civil Engineering, Vol. 2019, ID: 5290690. https://doi.org/10.1155/2019/5290690 
Wang, Q., Guo, Z., Mintah K., Li, Q., Mei, T., \& Peng, L. (2018). Cell-based Transport Path Obstruction Detection Approach for 4D BIM Construction Planning, American Society of Civil Engineers. https://doi.org/10.1061/(ASCE)CO.1943-7862.0001583

Woo, J. H. (2006). BIM (Building Information Modeling) and Pedagogical Challenges, $43^{\text {rd }}$ ASC National Annual Conference, Flagstaff, AZ, April 12-14. http://ascpro0.ascweb.org/archives/2007/CEUE169002007.pdf

Wu, W., Clevenger, C., \& Abdallah, M. (2018). Emerging faculty role in open digital learning, AiC, the 13th Annual AiC Conference Las Vegas, USA, 2018. https://aicbimed.com/files/proceedingsbimas2018a_2.pdf

Youssef, A. B., Youssef, H. B., \& Dahmani, M. (2013). Higher education teachers e-skills and the innovation process, International Journal of Computer and Information Technology, 2(2), March 2013. www.ijcit.com185, http://ijcit.com/archives/volume2/issue2/Paper020202.pdf

\section{Copyrights}

Copyright for this article is retained by the author(s), with first publication rights granted to the journal.

This is an open-access article distributed under the terms and conditions of the Creative Commons Attribution license (http://creativecommons.org/licenses/by/4.0/). 